the northern hemisphere could some time or other visit Australasia. Prof. Lawson, in the name of the University, offered the full hospitality of the botanical laboratory to visiting botanists.

The Botany School of the University of Sydney is a monument to the zeal, capacity, and artistic sense of Prof. Anstruther Lawson. The school has already a large and growing body of students and a highly creditable list of published researches.

E. C. J.

\section{Animal Breeding Research Department, University of Edinburgh.}

$\mathrm{W}$ $\mathrm{E}$ have received from the Director, Dr. F. A. E. Crew, the sixth annual report of the Animal Breeding Research Department of the University of Edinburgh. This department has recently received two large benefactions, namely, $£ 10,000$ from Lord Woolavington toward a fund for converting the directorship into a University chair, and $£ 30,000$ for general purposes from the Rockefeller Fund, so that the Department has the happy prospect of enlarging the scope of its work.

The report before us contains the list of a large number of problems of inheritance which are being attacked, but the progress made with the solution of any of them seems to be but moderate. All of them will require a long stretch of years before any considerable advance is made towards their solution, and in the case of domestic animals, the numbers with which it is possible to deal are too small to justify a successful analysis into Mendelian 'factors.'

More striking results are obtained from the investigation of endocrine reactions. We may direct attention to some extremely interesting results of extirpation of gonads in the mouse obtained by Mr. Kasur. The weight of the male remains unchanged, that of the female increases, but the kidney of the normal male is much heavier than that of the normal female, whereas the thymus and spleen of the former are considerably lighter than those of the latter. After castration the kidney of the male decreases whilst the thymus and spleen increase in weight, so that in all these respects the animal approaches the female type.

Another thought-provoking result was obtained by Mr. A. W. Greenwood acting in collaboration with the Director. He grafted into the body of a female chick four days old, after removing her ovaries, the testes of her brother. The bird assumed the plumage of the cock. 'This is in accordance with Zawadovsky's interesting results, in which he converted a cock into a hen and vice versa by the transposition of the gonads. But in the case under consideration the bird, after a subsequent moult, reverted to the plumage of the hen. A post-mortem examination revealed the fact that a small fragment of the functional left ovary had been left in the body by the operation, but that this remnant had degenerated. Not only, however, had the testis grafts survived and produced an abundance of testicular tissue, but ovariotomy had stimulated the vestigial right ovary to activity and it had also produced testicular tissue, so that the bird was in fact over-masculinised. Messrs. Greenwood and Crew advance the hypothesis that the ovary exercises a heavier drain on metabolism than the testis, and that the distinction between male and female secondary sexual characters is due to the degree of strain exercised on the organisation by the respective gonad in each case. If the testis is artificially increased in bulk beyond the normal, it exercises a strain equal to that of the ovary, and hence the secondary sexual characters of the female are produced.

E. W. M.

\section{Experiments on Molecular Complexity.}

PROF. H. BRERETON BAKER, for his presidential address at the annual general meeting of the Chemical Society on Mar. 24, chose as his theme "Experiments on Molecular Complexity." $\mathrm{He}$ had claimed that, like Sir Isaac Newton, " hypotheses non fingo," but, speaking later at the anniversary dinner, admitted that he was an inveterate maker of hypotheses, which, however, he forbore to publish.

The investigations described in the address arose out of the observation, some five years ago, that if liquids of very varying types were subjected to prolonged drying, the boiling points were raised to a very considerable extent. This rise, ascribed to an increase in the complexity of the molecules, takes place with typically unassociated liquids; hence it may be that all liquids are capable of association. Since water can also promote dissociation, it is conceivable that its absence might influence the molecular complexity in opposite directions; so far, however, dry liquids boiling at subnormal temperatures have not been obtained, although dry benzene has been separated into fractions boiling at $80^{\circ}$ and $118^{\circ}$ respectively. Further researches were carried out to see if catalysts other than water are effective, the experimental methods involving measurements of vapour density and surface tension.

Preliminary experiments in barometer tubes with very pure sugar charcoal gave definitely positive, although not quantitatively reproducible, results. For example, the vapour pressure of ethyl ether at $16^{\circ}$ was raised by $25 \mathrm{~mm}$., of methyl alcohol at $35^{\circ}$ by $12 \mathrm{~mm}$., and of benzene at $23^{\circ}$ or $37^{\circ}$ by $2 \mathrm{~mm}$. Prolonged experiments with Smith and Menzies' methods still gave variable results - a circumstance which has led Prof. Baker to two somewhat important deductions. First, a catalyst evidently acts very slowly, and sometimes in a direction contrary to that shown in the final equilibrium; secondly, a pure liquid appears to have no constancy of composition, but possesses a vapour pressure which depends on the history of the specimen. It therefore became necessary to employ a method by which the vapour pressure of the liquid could be balanced against that of the liquid with the catalyst.

Such a method made use of a U-tube containing mercury, the horizontal upper ends each carrying a pair of bulbs, and being connected by a capillary tube. The liquid could thus be distilled on to a catalyst, the capillary junction closed, and the difference arising between the vapour pressure of the pure liquid and that in contact with the catalyst could be directly measured. Acetic acid, benzene, methyl alcohol, ether, and bromine were examined, the catalysts being charcoal, platinum black, or thoria. In every case the catalyst caused an increase in the vapour pressure of the liquid; such a difference was, indeed, clearly apparent in a sample tube exhibited. An even more striking exhibit was a two-limbed tube in which, three weeks previously, accurately measured equal volumes of bromine had been placed, one of the limbs also containing charcoal. After evacuation, the tube had been sealed; so much bromine had afterwards distilled from the limb containing the catalyst that the charcoal was left almost dry. A refinement of the barometer tube method showed that the difference was increased by heating and diminished by cooling; heating and afterwards cooling to $20^{\circ}$ always caused an increase in vapour pressure, and cooling the reverse, the original value for a particular catalyst being restored only after some weeks.

For the surface tension measurements Ramsay and Shields' method was employed, the diameters of the

No. 2996, Voc. 119] 